\title{
Opportunities in Pulse Combustion
}

D. L. Brenchley

H. J. Bomelburg

October 1985

Prepared for the U.S. Department of Energy under Contract DE-AC06-76RLO 1830

Pacific Northwest Laboratory

Operated for the U.S. Department of Energy by Battelle Memorial Institute 


\title{
DISCLAIMER
}

This report was prepared as an account of work sponsored by an agency of the United States Government. Neither the United States Government nor any agency thereof, nor any of their employees, makes any warranty, express or implied, or assumes any legal liability or responsibility for the accuracy, completeness, or usefulness of any information, apparatus, product, or process disclosed, or represents that its use would not infringe privately owned rights. Reference herein to any specific commercial product, process, or service by trade name, trademark, manufacturer, or otherwise, does not necessarily constitute or imply its endorsement, recommendation, or favoring by the United States Government or any agency thereof. The views and opinions of authors expressed herein do not necessarily state or reflect those of the United States Government or any agency thereof.

\author{
PACIFIC NORTHWEST LABORATORY \\ operated by \\ BATTELLE \\ for the \\ UNITED STATES DEPARTMENT OF ENERGY \\ under Contract DE-AC06-76RLO 1830
}

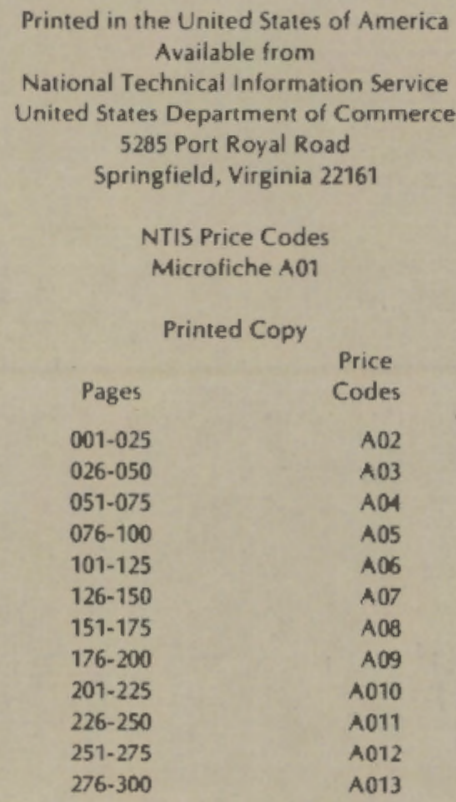


0. L. Brenchley

H. J. Bomelburg

October 1985

Prepared for Energy Conversion and Utilization Technologies Oivision Office of Energy Systerns Research Conservation and Renewable Energy U.S. Department of Energy under Contract OE-AC06-76RLO 1830

Pacific Northwest Laboratory Richiand, Washington 99352 
: 
Combustion processes do not always proceed under steady-state conditions but can oscillate more or less violently. Usually such combustion instabilities are highly undesirable because they generate strong noise and vibrations, and special measures have to be taken to avoid damage to the combustion equipment. Such undesired combustion-driven oscillations have been widely reported in gas turbines, rocket engines, flares in refineries, blast furnaces, etc. However, under certain conditions and for special applications, these pulsating combustion phenomena have been found to actually improve combustion efficiency and thus save fuel. Therefore, under controlled conditions, pulse combustion can be desirable from an energy conversion perspective.

In pulse combustion, burning occurs in a tube in an oscillatory manner, in contrast to the steady-state combustion used in most boilers and furnaces. In most pulse combustors, the combustion occurs near the closed end of a tube where inlet valves operate in phase with the pressure amplitude variations. Thus, within the combustion zone, both the temperature and the pressure oscillate around a mean value. However, despite this seemingly simple arrangement, the development of practical applications of pulse combustion has been hampered because effective design requires the right combination of the combustor's dimensions, valve characteristics, fuel/oxidizer combination, and flow pattern.

Pulse combustion has several additional demonstrated advantages for energy conversion efficiency, including high combustion and thermal efficiency, high combustion intensity, and high convective heat transfer rates. ATso, pulse combustion can be self-aspirating, generating a pressure boost without using a blower. This allows the use of a compact heat exchanger that may include a condensing section and may obviate the need for a chimney. In the last decade, these features have revived interest in pulse combustion research and development (R\&D), which, for example, has resulted in a commercial pulse combustion air heater for domestic use developed by lennox, and a pulse combustion hydronic unit developed by Hydrotherm, Inc. These units can operate up to $96 \%$ 
efficiency, whereas most standard gas hot water heaters usually operate from $55 \%$ to $78 \%$. Such applications demonstrate the potential for energy savings with pulse combustion.

To appraise this potential more definitively, Pacific Northwest Laboratory (PNL) (a) conducted a systematic study of the many past and present attempts to use pulse combustion for practical purposes. The study was conducted for the Energy Conversion and Utilization Technologies (ECUT) Division of the Office of Energy Systems Research, U.S. Department of Energy (DOE). The authors recommended areas where pulse combustion technology could possibly he applied in the future and identified areas in which additional R\&D would be necessary. The findings of this study are presented in an extensive report. (b) Many of the results of the study project derived from a special workshop on pulse combustion in which currently active researchers in this field participated. This document highights the main points of the study report, with particular emphasis on pulse combustion application in chemical engineering.

(a) Pacific Northwest Laboratory is operated for the U.S. Department of Energy by Rattelle Memorial Institute.

(b) Brenchley, D. L. and H. J. Bomelburg. 1984. Pulse Combustion -- An Assessment of Opportunities for Increased Efficiency. PNL-530I, Pacific Northwest Laboratory, Richland, Washington. This report contains an extensive literature review (about 180 references) and also detailed results of the 1984 Pulse Combustion Workshop. 
1.0 PRINCIPLES OF PULSE COMBUSTION $\ldots \ldots \ldots \ldots \ldots \ldots \ldots \ldots \ldots \ldots \ldots \ldots \ldots \ldots \ldots \ldots \ldots, 1.1$

2.0 PRACTICAL APPLICATION AND OPPORTUNITIES FOR PULSE COMBUSTION TECHNOLOGY

2.1 PULSE COMBUStION APPLICATIONS IN DEVELOPMENT $\ldots \ldots \ldots \ldots \ldots \ldots, ? .5$

2.2 NEW APPLICATIONS IN CHEMICAL TECHNOLOGY $\ldots \ldots \ldots \ldots \ldots \ldots \ldots .2 .6$

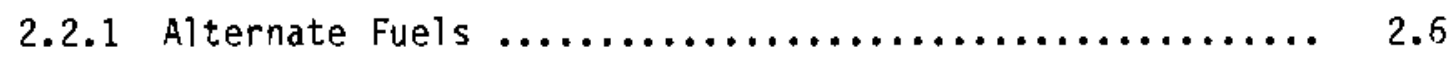

2.2.2 Chemical Reactors $\ldots \ldots \ldots \ldots \ldots \ldots \ldots \ldots \ldots \ldots \ldots \ldots, 2.6$

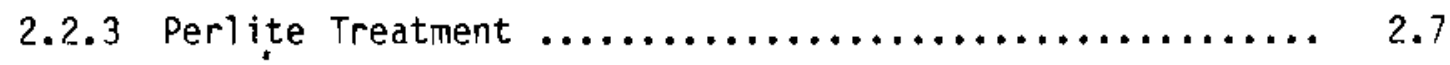

2.2.4 Fluidized Beds $\ldots \ldots \ldots \ldots \ldots \ldots \ldots \ldots \ldots \ldots \ldots \ldots, 2.7$

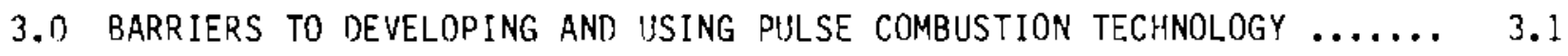

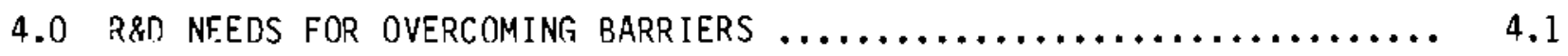

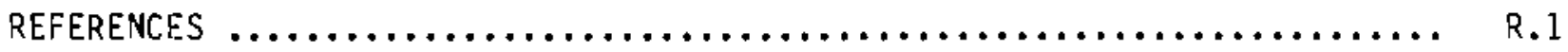





\subsection{PRINCIPLES OF PULSE COMBUSTION}

In all pulse combustion applications, the basic principle is essentially the same (Figure 1.1). Fuel and air are admitted to a combustion chamber through more or less effective one-way valves. A pressure wave, generated by the initial ignition, travels down the exhaust tube. Due to inertial effects, a partial vacuum is caused in the combustion chamber, which then draws in additional fuel and air. At the end of the exhaust tube, the pressure wave is partly reflected. This results in some compression of the gas in the combustion chamber where the newly admitted fuel/air mixture is ignited, presumably by mixing with the hot gases of the preceding cycle. The cycle then repeats itself indefinitely. The cycle phase is timed such that the geometrical combustion chamber/exhaust tube configuration is acoustically at resonance. The frequency is usually in the 60 to $90 \mathrm{~Hz}$ range. It has been found that "combustion intensity" (heat generated per unit volume) for pulse combustors is typically one order of magnitude higher than for ordinary combustion.

A complete understanding of pulse combustion is difficult to achieve because it simultaneously involves several disciplines, and few scientists and engineers, if any, are true experts in all these fields. The disciplines involved include thermodynamics, fluid mechanics, combustion chemistry, acoustics, mechanical engineering, and possibly a few others such as environmental safety. Most of the published basic papers on pulse combustion deal with only certain aspects authoritatively, while making more or less subjective assumptions on others. The bulk of the literature describes test results with only tentative or incomplete explanations on a fundamental basis. Therefore, a great deal of empirically obtained data exist, but apply only to a very limited range of configurations.

Many different configurations of pulse combustion have been proposed and tested over the years. In particular, "aerodynamic valves," which generate higher flow resistance for the backflow than for the ingoing flow, often have been tried as a substitute for mechanical check valves. (They are most useful primarily in propulsion devices, such as the "pulse-jets"). Figure 1.2 shows the phases of a pulse combustion cycle that uses such aerodynamic valves (Corliss et al. 1983). 


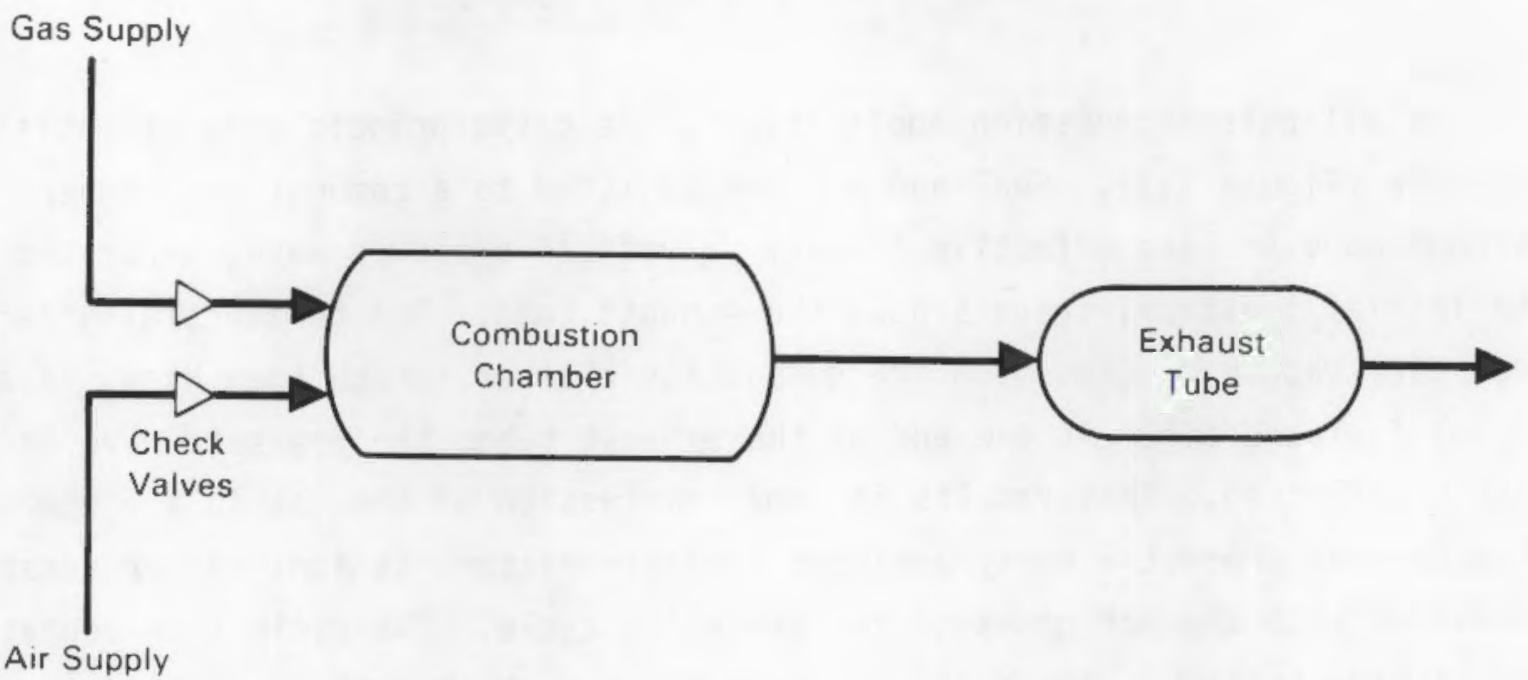

\section{Block Diagram Model}

FIGURE 1.1. Basic Principle of Pulse Combustion (Coulman et al. 1982)

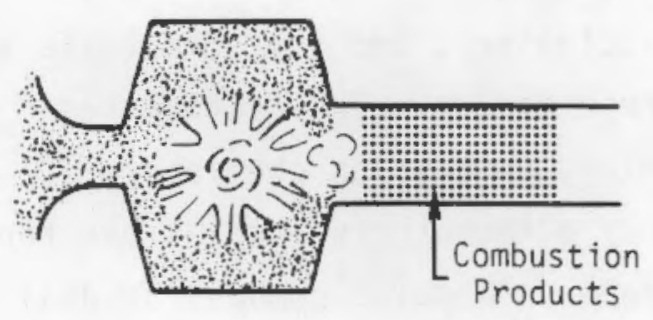

1. Ignition and Combustion

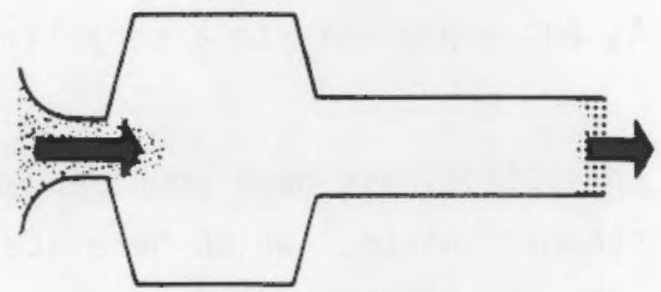

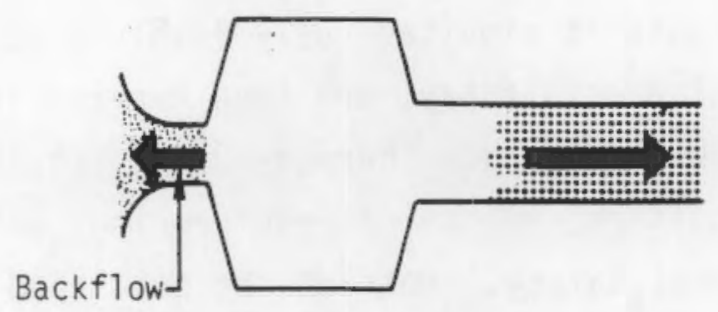

2. Expansion

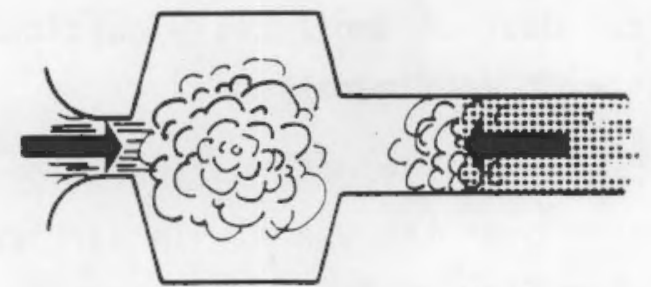

FIGURE 1.2. Operating Phases of an Idealized Pulse Combustor -Aerovalved Type (Corliss et al. 1983) 


\subsection{PRACTICAL APPLICATION AND OPPORTUNITIES FOR PULSE COMBUSTION TECHNOLOGY}

Over the years, many industrial companies have attempted to develop and manufacture pulse furnaces and hot water heaters. The initial emphasis has been on home heating units. Pulse combustion is now also being applied to drying processes. Some of the early efforts to apply pulse combustion to home heating units were fostered and supported by organizations such as the American Gas Association (AGA) and the Gas Research Institute (GRI).

As an example, a pulse combustion furnace that is now offered by Lennox, Inc., was originally developed under the sponsorship of the AGA, starting in 1978. Later, GRI furthered the development. Extensive field tests were conducted on the resulting system, and commercial production, licensed to Lennox, began in 1982. Input capacities range from 40,000 to $130,000 \mathrm{Btu} / \mathrm{hr}$, and purchase costs roughly range from $\$ 2000$ to $\$ 3000$. Lennox is currently conducting an active advertising campaign for this furnace.

Hydrotherm, Inc., offers gas-fired heating systems that range from 50,000 to $150,000 \mathrm{Btu} / \mathrm{hr}$ under the trade name Hydropulse $\mathrm{m}^{\mathrm{m}}$ (a) These units have been commercially available since about 1980, after two gas companies tested them in private homes in New York and Minnesota. The design apparently is a follow-on to a Canadian model offered under the name "Pulsamatic" from about 1960 to 1966 by Greensteel Ltd. of Winnipeg. That model had been developed by Lucas Rotax, Ltd. (Toronto) and, in turn, was an update of a model called "Swingfire," developed during the early 1950s in Germany and based on the V-1 buzz bomb of World War II.

The Lennox pulse combustion furnace is shown in Figure 2.1 and the Hydropulse hot water heaters in Figures 2.2 and 2.3. Various other IJ.S. companies are currently (or have been in the past) working on developing pulse combustor air or water heating systems, but no commercial production has resulted so far.

In Germany, several versions of the "Swingfire" device have been available since about 1950. These portable devices can be adapted to many end uses. In particular, they have been used for rapid heating of commercial vehicles (e.g.,

(a) Trademark of Hydrotherm, Inc. of New Jersey. 


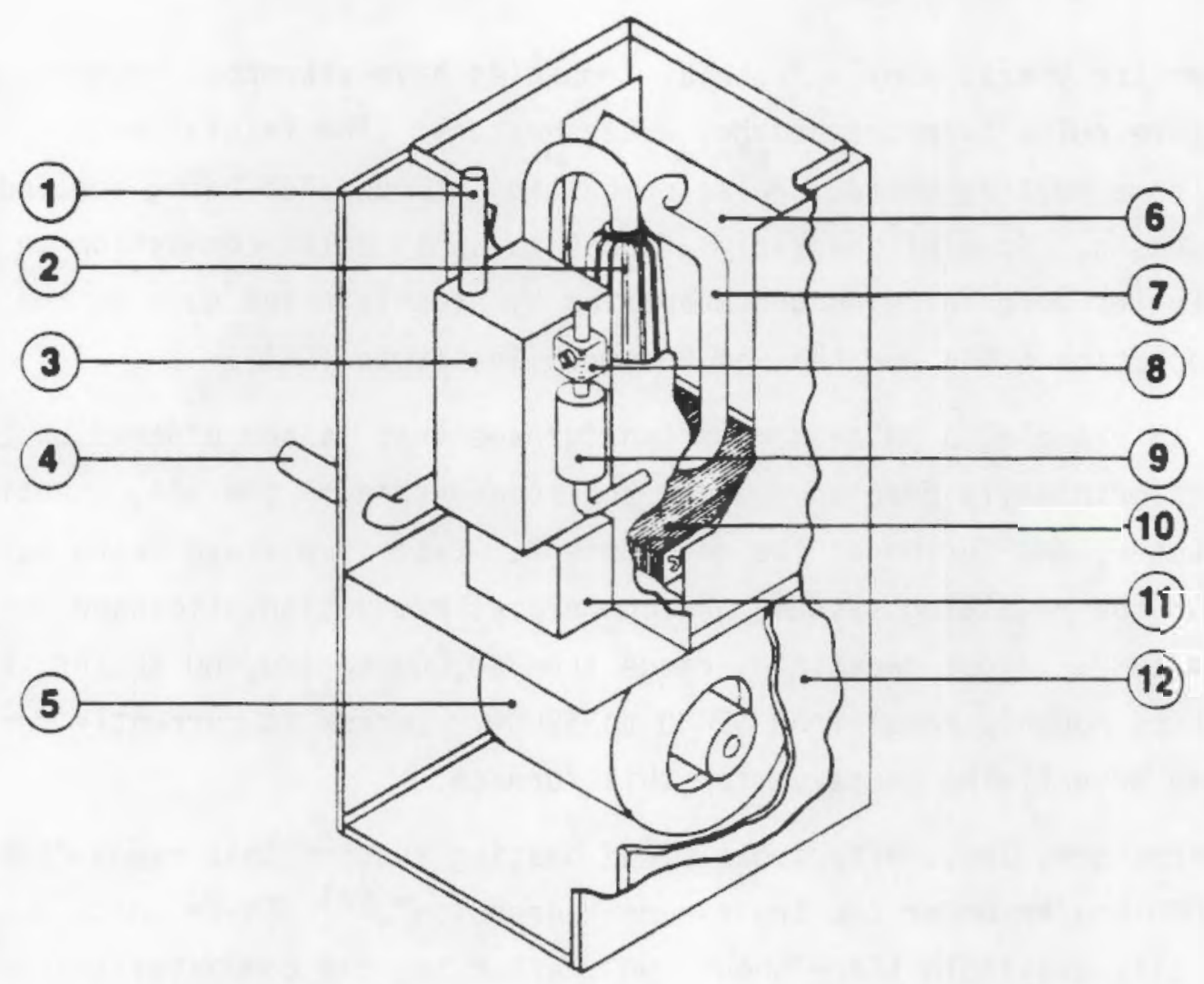

(1) AIR INTAKE

(2) COMBUStION ChAMBER

(3) AIR DECOUPLER

(4) VENT PIPE

(5) blower

(C) exhaust decoupler
(7) EXHAUST PIPE

(b) Gas valve

(9) Gas decoupler

(10) CONDENSING HEAT

(11) EXCHANGER

(12) FILTER

FIGURE 2.1. Schematic of Lennox Pulse Combustion Furnace (Adams 1982) 


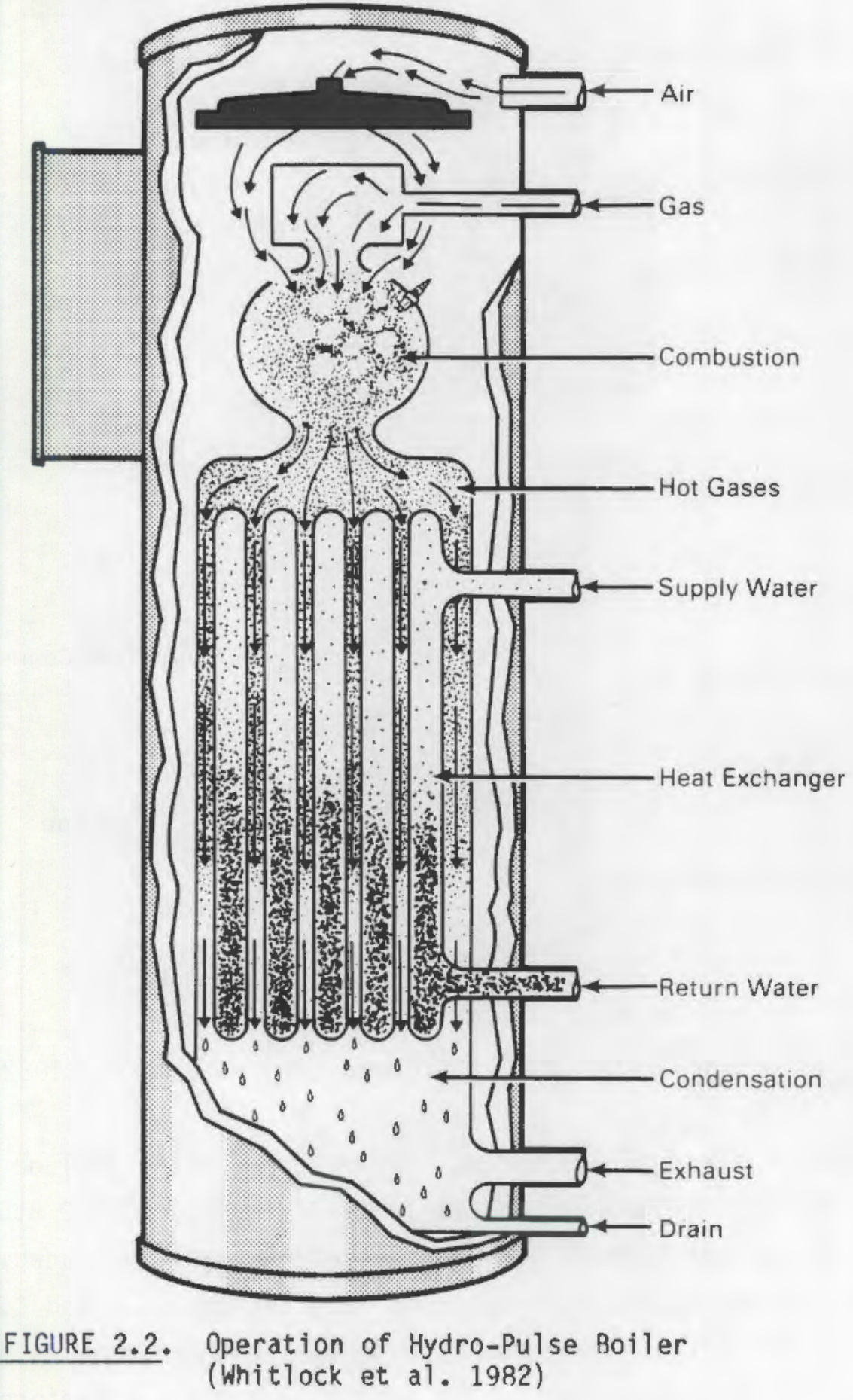




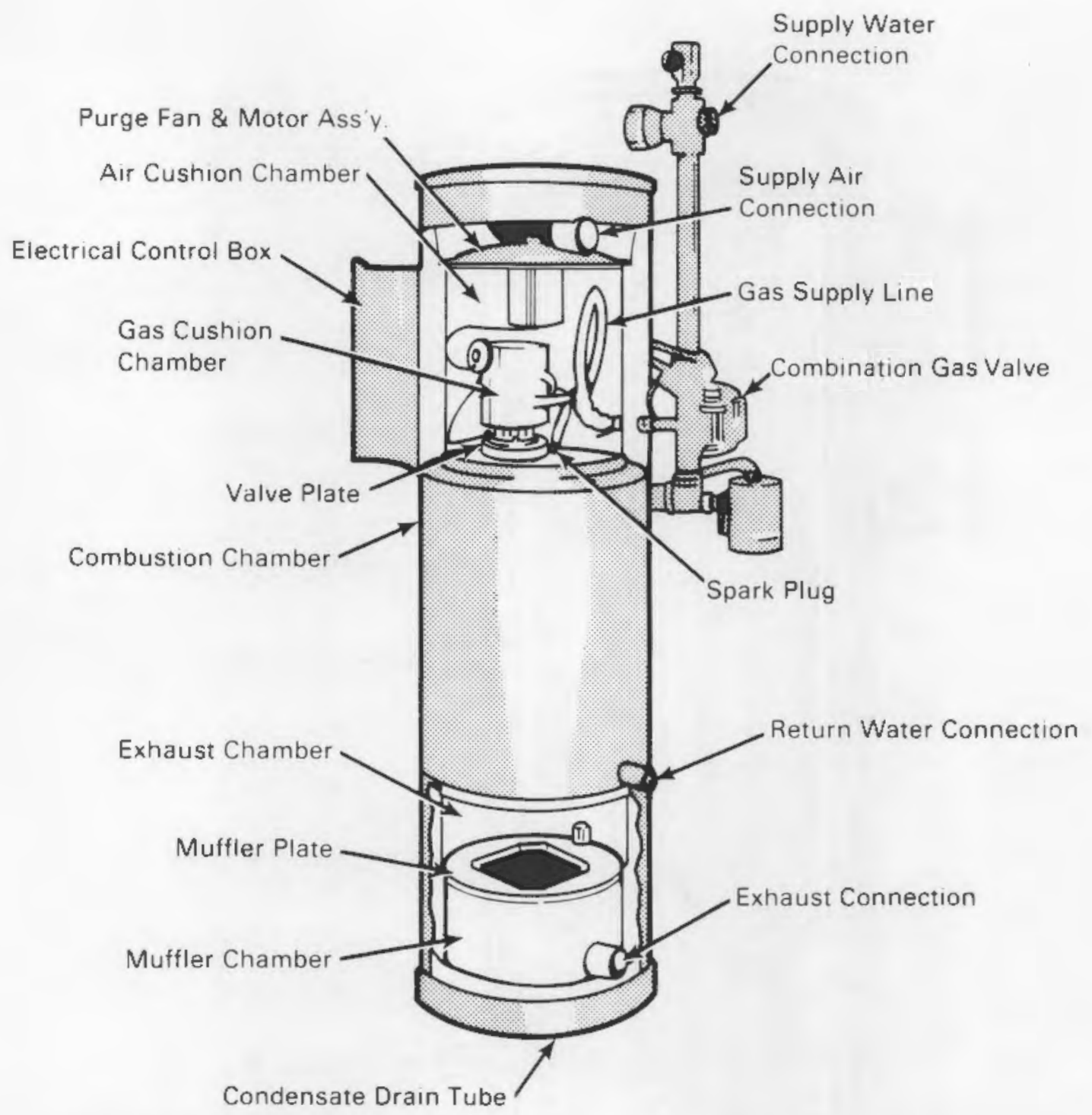

FIGURE 2.3. Hydro-Pulse Boiler Cutaway (Whitlock et al. 1982)

fire trucks), small buildings, and tents. Other applications include de-icing and rapid water heating. Power leyels are typically about $600,000 \mathrm{Btu} / \mathrm{hr}$ $(175 \mathrm{~kW})$. Some Swingfires operate at $90 \mathrm{~Hz}$ and may be heavily loaded. In their combustion chambers, pressures can oscillate between 0.75 and $1.4 \mathrm{~atm}$ absolute (10.5 and 20 psia). Consequently, the peak exit velocities of the combustion gases can reach $150 \mathrm{~m} / \mathrm{sec}$. The exhaust gases are therefore able to drive small turbines, which in turn drive fans to circulate the air through heat exchangers when a unit is used for air heating.

In the USSR many pulse combustor applications have been reported (Severyanin 1982). These applications include soot cleaning, fume suppression, 
burning rate enhancement of various particulate fuels, particle coagulation, fluidized bed combustion, etc. Netailed descriptions of the various devices are difficult to obtain because most of the pertinent publications are in Russian. However, most of the devices apparently were built for special industrial applications (possibly one of a kind) and have not been manufactured for sale on the open market.

In addition to home heating units, pulse combustion has also been applied to drying processes (Lockwood 1979). At least two companies (Sonodyne and Sonic Corp.) in the I.S. have applied pulse combustion to commercial drying processes. The Sonic Corporation in Idaho has developed a highly successfu? method for drying yeast in breweries. The raw liquid material is injected by metering pumps directly into the hot gas $\left(2300^{\circ} \mathrm{F}\right)$. Once in the gas, the material is almost instantly atomized into finely divided particies, with most of the moisture converted to steam. The mixture is then blown into a big cyclone (14 ft dia, $30 \mathrm{ft}$ high) where further drying occurs and $80 \%$ of the yeast (with approximately $5 \%$ moisture left) is taken out. The rest of the yeast is collected in a baghouse. The pulse combustor is run at maximum efficiency and is controlled by monitoring off-gas temperature. The operation is continuous ( 7 days a week), which results in a very consistent quality of the yeast. Daily output equals the volume of approximately 5 tank trucks. The quality of yeast is ciaimed to be higher than that of the competition, which uses more conventional drying methods. Because of the fast drying rate, the yeast's nutrients supposedly are retained, whereas they are largely destroyed in the conventional, slower methods.

\subsection{PULSE COMBUSTION APPLICATIONS IN DEVELOPMENT}

The Gas Research Institute (GRI) currently has by far the most active role in furthering pulse combustion technology (Johnson et a?. 1984). It not only supports general R\&D work at various laboratories but also supports the actual development of additional pulse combustion applications for domestic and commercial gas-fired appliances, such as larger residential and commercial air and water heaters, commercial cooking equipment, griddles, deep-fat fryers, etc. 
Steam boilers are also presently under development. These projects are carried out in close cooperation with U.S. firms that manufacture conventional equipment of this sort.

\section{2.? NEW APPLICATIONS IN CHEMICAL TECHNOLOGY}

Several potential applications for pulse combustion technology have been identified and are described below.

\section{2.?.1 Alternate Fuels}

The most suitable and convenient fuels for pulse combustion are obviousiy gaseous fuels. However, it has been demonstrated that liquid and solid fuels can also be burned in pulse combustors, even though units of this type are not yet available commercially. Solid fuels that have been tested include pulverized coal, lignite, wood chips, and other low-grade fuels. It even appears that combustion can be more complete for such fuels if they are burned in a pulse combustor.

Tests have shown that pulverized and even unpulverized coal can be burned at a much faster rate (10 to 20 times faster) in a pulse combustor than in a regular burner. As a consequence, the combustion intensity, i.e., heat generated per unit volume, is greatly increased. For stoichiometric conditions, it has been observed that values on the order of $50 \times 10^{6} \mathrm{Kcal} / \mathrm{m}^{3} \mathrm{hr}$ are obtainabie for pulverized coal combusted with air. For such reasons, it appears likely that coal slurries can also be burned in pulse combustors more efficiently than in steady-state burners, especially if burned with oxygen-enriched air or pure oxygen.

\subsubsection{Chemical Reactors}

Another potential area for future applications of pulse combustion is chemical processing in reactors. Because turbulent heat and mass transfer can be considerably increased in a pulsating environment, the speed of chemical reactions, which depend on molecular interaction between the participating species, would increase. Calcining processes would probably be the initial applications. PuTse combustion has al ready been successfully demonstrated in lime calcination (Rudoiph et al. 1978). Another possibility would be to apply 
pulse combustion to catalytic processes in which the oscillating movements of the hot gas environment would increase the rate of interchange between catalytic and reacting particles. To date, this possibility has apparently never been studied. Pulse combustion could also be used in coal gasification operations, as was demonstrated more than 30 years ago (Traenkner 1952).

In still another application (Ehnert et al. 1977), tests conducted by an industrial coke oven facility in Germany have shown that raw coke oven gas (a) can be made more useful by partial oxidation in a pulse combustor with oxygen or oxygen-enriched air. The resulting gas consists mainly of $\mathrm{H}_{2}(65 \%)$ and $\mathrm{CO}$ $(25 \%)$ and as such, is usable as a reducing or synthesis (b) gas in the chemical industry. It has been claimed that in such a process, the high combustion intensity of the pulse combustion process causes not only the breakup of high molecular carbohydrates (including condensed carbohydrates), but also the partial oxidation of agglomerated carbon particles.

\subsubsection{Perlite Treatment}

In tests conducted in Czechoslovakia, it has been demonstrated that pulse combustors can be used to produce expanded perlite (Fabianova 1976). Raw perlite (a glassy igneous rock), ground to particles in the order of 1 um, has been passed through a pulse combustor where it expands to a highly porous material that can be used as a high-temperature insulating material.

\subsubsection{Fluidized Beds}

Another potential application might be using pulse combustion in fluidized beds. In recent years, fluidized bed combustion has gained industrial acceptance, even though the development of this relatively new technology is still

continuing, particularly for pressurized fluidized beds. If pulsations are present in the flow, it can be expected to cause an increase in the mixing of the species that participate in the combustion process, thereby effectively

\footnotetext{
(a) Raw coke oven gas, consisting mainly of condensible carbohydrates mixed with solid carbon particles, is a low-Btu (about 500 Btu/ft ${ }^{3}$ ) fuel gas and is primarily used for heating purposes near its place of origin (e.g., in steel plants) because its transportation over longer distances is generally not feasible or economical.

(b) Synthesis gas is commonty used for the catalytic synthesis of methane.
} 
improving the mass exchange and the heat transfer within the bed. This should result in more complete combustion, in a cleaner exhaust, and in a more compact facility. Because self-sustaining oscillations probably cannot be generated in fluidized beds, it must be assumed that the pulsating flow has to be artificially generated from the outside, for example, by pulsating the air supply. 


\subsection{BARRIERS TO DEVELOPING AND USING PIJLSE COMBUSTION TECHNOLOGY}

Since Reynst (1961) first described the potential for pulse combustion in the 1930 s and 1940 s, predictions have been made that this new technology would "revolutionize combustion and gasmaking practice." Despite many attempts to introduce pulse combustion on a wide scale, however, it still remains a relatively obscure technology, widely unknown even in industrial circles.

Several harriers have been identified as hindering the development and use of pulse combustion technology: its noise, lack of awareness of the technology, lack of design and evaluation procedures, lack of credibility, the higher cost of pulse combustion equipment compared with conventional combustors, and lack of an infrastructure to move the technology into the market place.

Clearly, the most obvious negative attribute of pulse combustion has been its intense noise (up to 140 decibels). Silencers (mufflers) therefore must be used to reduce the noise to an acceptable level. Much effort has been spent on this problem, and it has been demonstrated repeatedly that with proper design, the emitted noise can be reduced to below 60 decibels. However, this reduction cannot be achieved routinely in any new configuration and usually considerable testing is required. With increasing experience in this field, general design rules might be expected to evolve, which then would reduce developmental testing considerably. Unfortunately, the current fundamental understanding of the complexities of pulse combustion is still incomplete.

Another basic problem is that reliable mathematical models for design and scaleup do not exist. The common approach for developing a pulse combustor for a specific purpose has been trial and error. This approach can be tedious, particularly if optimization is required, which is nomally the case. Having analytical methods with wich to design and evaluate a particular device without extensive testing would be highly desirable. However, the physical and chemical phenomena that comprise the pulse combustion process need to be better understood before these methods can be developed. Inderstanding these phenomena would require considerable systematic research rather than the previously used ad hoc research. 
Another barrier in developing and using pulse combustion technology is that the potential of pulse combustion is still largely unknown except for a few engineers who have a special interest in this field. The most effective way to overcome this obstacle appears to be by introducing actual equipment, as exemplified hy GRI's approach of subsidizing the development of various appliances for domestic and commercial use.

Because pulse combustion is still generally considered a new, untried technology (even though it has existed for over 40 years), engineers are often somewhat skeptical about the reliability and durability of pulse combustors, especially those with mechanical valves. Except for certain propulsion devices, the aerovalves used in pulse combustion may appear questionable to many people, since aerovalves all deviate more or less from a desirable perfect performance. Because the valves have always been the most critical part in pulse combustors, the reservations are justified. Therefore, only favorable, long-term, practical experience with standard manufactured devices is likely to remove such skepticism.

Another barrier to introducing pulse combustion has been the relatively high cost of such equipment compared to more conventional combustors. Industry is now trying to reduce the manufacturing costs by adapting proven mass production methods. It appears possible that the cost of heating systems can be reduced far enough so that the energy saved in a few years will pay for the extra cost of installing a pulse combustion heater instead of a conventional furnace. For example, the Lennox residential heating system now appears to be gaining momentum because of its proven high efficiency and quality.

Engineers in industry also perceive the lack of communication among scientific, engineering, manufacturing, and marketing institutions as a major barrier to introducing pulse combustion. Also, installers of pulse combustion heaters seem to have very limited experience. It would be desirable that these entities work together as a team to develop and commercialize not only new pulse combustors but entire puise combustion systems. Obviously, a combustor by itself has little usefulness unless it is integrated into a well-functioning and compact system, including proper control and safety measures, that has a way of reaching the marketplace. 


\subsection{R\&D NEEDS FOR OVERCOMING BARRIERS}

Since the 1930s, pulse combustion has been the subject of both theoretical and experimental R\&D. However, most of this work has been performed on an ad hoc basis, aimed at a specific device. Therefore, even though a considerable amount of practical experience exists, the fundamental understanding of the pulse combustion process itself is still largely incomplete.

A primary goal of such fundamental and applied R\&D work in pulse combustion would therefore be to advance the state of the art to allow a pulse combustor to be designed for a specific purpose from basic principles, without requiring extensive developmental testing on a trial-and-error basis. Other goals would be to examine new areas in which pulse combustion could be used and ways to optimize existing and new pulse combustion devices.

Quite generally, the phenomena of pulsating flow are extremely complex, especially if they involve heat and/or mass transfer. Fluid dynamicists have therefore oniy occasionaliy dealt with these phenomena on a strictly fundamental basis. Additionally, knowing the extent to which the heat generated in the combustion process can be extracted, transferred, and used for a specific end use is also highly important for successful developments and applications. Combustion putsations and heat transfer characteristics are known to be interdependent, but a valid quantitative formulation of this relationship is not yet available.

Furthermore, a method to analyze the flow through inlet valves of pulse combustors has never been satisfactorily developed and therefore al so merits continued study. This study would be particularly appropriate for the aerodynamic type of valve for which many configurations have been proposed and tried. It is quite possible that the largely neglected fluidic vortex valves would provide promising alternatives and should therefore be given special attention.

Fundamental phenomena encountered in oscillating combustion also have been studied. Again, although such work was not intended to further pulse combustion technology, it can still provide valuable insight into phenomena that are identical or closely related to those found in pulse combustion. 
Unfortunately, even without combustion, pulsating flow in pipes and ducts is in itself still quite complex, especially if the flow is turbulent (which it normally is in combusting flows). Only very recently have fluid dynamicists begun to systematically investigate the important role that turbulence plays in pulsating flows. For example, a special wind tunnel has been built in which pulsating flows can be experimentally investigated (Borell et al. 1984). Aithough combustion phenomena are not included in these very recent efforts, they represent a first direct approach from which a complete understanding of pulse combustion phenomena based on first principles could eventually evolve.

Recause the general fundamental research mentioned above is necessarity long term, it is not likely to produce immediate results that could aid in energy conservation in the near future. This was also the opinion of the participants of the 1984 Pulse Combustion Workshop. They thought that fluid flow and combustion merit priority attention separately as well as interactively. Such work is ultimately hoped to lead to a useful mathematical morlel for pulse combustion. Such a model would also be needed to develop a method for scaling pulse combustors so that reliable conclusions could be drawn from model testing at reduced scale. This modeling could then considerably decrease the cost of developing new pulse combustion systems.

The need to reduce noise levels of putse combustors below a certain level (55 to 60 DBA) before pulse combustors can become more widely acceptable also requires additional work. The most effective way to control noise appears to be operating two or more phase-synchronized pulse combustors in paraliel. Systematic research could probably develop reliable methods to achieve this synchronization. Such work would be particularly important for pulse combustion systems operating at higher amplitudes, since they also generate higher noise levels.

As noted above, most existing commercial pulse combustors are fueled by natural gas or other types of gaseous fuels, and experience with liquid and solid fuels has so far largely been limited to research projects that have merely demonstrated that such fuels can be burned in pulse combustors. Additional R\&D work is now needed to further develop these pulse combustion devices so that they can be manufactured at a reasonable cost for practical use in 
industrial or commercial applications. Of particular interest would be commercial pulse combustors for coal. The modes of operation of such combustors need to be investigated because they depend on many parameters, such as size and type of the burned coal, size and frequency of the combustor, pressure gains, heat transfer characteristics, and exhaust pollution. Attending problems such as ash handing, feed-mechanism for the ingoing coal, and control of output also need to be addressed before a working system for practical use can be assembled. The possibility of feeding coal slurries directly into a pulse combustor has not been examined to date, but appears to have considerable potential.

Many other solid fuels besides coal could be burned in pulse combustors. The low-grade fuels (e.g., lignite, peat, wood) particularly may be burned more effectively in pulse combustion than would be possible in regular combustion. As several experiments and minor applications have shown, liquid fuels (a wide variety of oils) can also be burned in pulse combustors. However, large-scale use of this possibility is still practically nonexistent, and additional R\&D work is necessary to develop practical systems. The possibility also may exist that a specially designed putse combustor could be operated on a variety of fuels, for example, gas and oil. Many liquid and solid wastes are best disposed of by incineration. The inherent higher efficiency of pulse combustion therefore is attractive for these special "alternative fuels."

Even though two U.S. companies already have commercial gas-fired units for drying purposes, research is needed to extend applications to other areas. The modes of drying seem to be 1) drying during passage of the material through the resonance tube, and 2) enhanced drying in the acoustic field outside the pulse combustor. Neither has been studied. Information is needed both on the types of materials that can be dried without damage and on the drying rates. Test data should be obtained as a function of time, humidity, frequency, and amplitude, and an analytical model should be developed.

Finally, the lack of awareness, infrastructure, and constituency are nontechnical barriers, but nevertheless are of high consequence for economic reasons. They can be initially addressed with a systems analysis study. 
Although pulse combustion is now being used in a few commercial applications, its potential is still largely unrealized in industry, apparently because its potential for industrial applications has either been overlooked or ignored. Pulse combustion began to he more seriously considered as a viable option only when the steep increase of energy costs about 10 years ago compelled combustion efficiencies to be improved. But so far, pulse combustion is being used on a relatively small scale, mainly for domestic and commercial heaters for which GRI claims that they can save $30 \%$ to $50 \%$ in fuel costs. A few other applications, such as the drying and dehydration processes, have also proved to be highty successful.

Such positive results indicate that many industries using heat in one form or another might also conserve a significant amount of energy by using the fundamentally very efficient pulse combustion process. A systematic examination of the entire spectrum of U.S. industries is needed to identify those having the largest potential for significant energy savings from pulse combustion. Cases considered would include power plants, chemical processing plants, external combustion engines, heat treating processes, etc.

Chemical processing has specific potential in this respect since many chemical processes require high temperatures to proceed efficiently, i.e., at a sufficient speed and degree of completion. However, frequently the high temperature needs to be present in the system for only a brief instant. In some cases, efficiency may be improved by providing peak temperatures only cyclically, rather than by keeping temperatures constant at a rather high level.

Thus, it appears worthwhile to bring the subject of pulse combustion to the attention of chemical engineers, particularly those who work with hightemperature processes. It is conceivable that they could propose many additional applications since they are the most familiar with the specific requirements and Iimitations of such processes. 


\section{REFERENCES}

Adams, C. W. 1982. "Performance Results of the Lennox Pulse-Combustion Furnace Field Trials." In Proceedings on Pulse-Combustion Applications, GRI82/0009.2, Vol. 1, Gas Research Institute, Chicago, Illinois.

Bore11, G. J., et al. 1984. "Pressure and Meat Transfer Measurements Around a Cylinder in Pulsating Crossflow." In Unsteady Turbulent Boundary Layers, ASME, FED-VOL. 12, pp. 17-23. Presented at Energy Sources Technology Conference, February 12-15, 1984, New Orleans, Louisiana.

Brenchley, D. L. and H. J. Bomelburg. 1984. Pulse Combustion - An Assessment of Opportunities for Increased Efficiency. PNL-5301, Pacific Northwest Laboratory, Richland, Washington.

Corliss, J. M., et a]. 1983. Aerovalved Pulse-Combustion Systems for High Efficiency Commercial/Industriat Boilers. GRI-80/0182, Gas Research Institute, Chicago, ITItnois.

Coulman, G. A., et a1. 1982. "Experimental Evaluation of a Pulse-Combustion Computer Simulation." In Proceedings on Pulse-Combustion Applications, GRI82/0009.2, Vol. 1. Tas Research Institute, Chicago, Tinoís.

Ehnert, W. et aT. 1977. Transport and Processing of Raw Coke Oven Gas at High Temperatures (in German). GWF-Gas/Erdgas 118:441-444.

Fabianova, J. 1976. "Pulsating Combustion and Its Utilization in the Production of Expanded Perlite." (in Slovak). Silikaty 4:363-370.

Johnson, 0. D., et a1. 1984. "Pulse Combustion--A Versatile Technology for High Efficiency Appliances." Gas Research Institute Digest. 7(3):4-11.

Lockwood, R. M. 1979. "Drying Food and Wastes with Pulsating Combustion." In Proceedings of the Symposium on Pulse Combustion Technology for Heating Applications. ANL-EES-TM-87, Argonne National Laboratory, Argonne, I1Tinois.

Reynst, F. H. 1961. Collected Works. Translated and edited by M. W. Thring, Pergamon Press, New York, New York.

Rudolph R., et al. 1978, "The Pulse-Combustor as Chemical Reactor." Chem. Tech (in German). 30(7):333-336.

Severyanin, V. S. 1982. "Application of Pulsating Combustion in Industrial Installations." In Proceedings on Pulse-Combustion Applications, GRI82/0009.2, Vol. 1. Gas Research Institute, Chicago, Intinois.

Traenkner, K. 1952. Gas from Low Quality Coal (in Geman). GWF 93(19):537547. 
Whitlock, D. J., et al. 1982. "Field Tests on Pulse-Combustion Boilers for Residential Space Heating and Domestic Water Heating." In Proceedings on Pulse-Combustion Applications, GRI-82/0009.2, Vol.1. Gas Research Institute, Chicago, IlTínois. 
DISTR IBUTION

No. of

Copies

OFFSITE

30 M. Gunn

U.S. Department of Energy

Energy Conversion and

lltilization 0ivision

IG-080 Forrestal Building

Washington, D.C. 20585

J. Brogan

U.S. Department of Energy

Offices of Energy Systems

Research

Washington, D.C. 20585

J. Kane

Rasic Energy Sciences

IJ.S. Department of Energy

ER-10

Washington, D.C. 29545

W. Thielbar

I).S. Department of Energy

Idaho Operations office

550 Second Street

Idaho Falls, ID 83401

30 DOE Technical Information Center

R. Holtz

Argonne National Laboratory

Building 330

9700 S. Cass Avenue

Argonne, IL 60439

F. Marble

Mechanical Engineering Dept.

California Institute of Technology

1201 East California Blyd.

Pasadena, CA 91125
No. of

Copies

\section{R. Abarcar}

Energetics, Inc.

9210 Route 108

Columbia, M0 21045

C. Fink

Energetics, Inc.

9210 Route 108

Columbia, MD 21045

M. Dastoor

The let Propulsion Laboratory

4800 Oak Grove Drive

Mail Stop 122-123

Pasadena, CA 91103

K. G. Kreider

U.S. Department of Comrnerce

National Bureau of Standards

Physics B-250

Washington, D.C. 20234

J. A. Carpenter

Oak Ridge National Laboratory

P.0. Box $x$

Building 4508 North Room 263

Oak Ridge, TN 37830

C. Ferguson

Department of Mechanicat

Engineering

Purdue University

West lafayette, IN $\mathbf{4 7 9 0 7}$

R. Edelman

SAI

9760 Owensmouth Avenue

Chatsworth, CA 91311

C. T. Bowman

Department of Mechanical

Engineering

Stanford University

Stanford, CA 94305 
No. of

Copies

G. Strasser

Strasser Associates, Inc. 2616 Pine Knot Drive

Vienna, VA 22180

S. E. Elghobashi

University of California

at Irvine

School of Engineering

35 Cool Brook

Irvine, $C A 92715$

A. A. Putnam

Battelle-Columbus Laboratories

Columbus, $\mathrm{OH}$ 43201-2693

J. F. Keller

EG\&G Idaho, Inc.

P.0. Box 1625

Idaho Falls, $10 \quad 83415$

J. A. C. Kentfield

University of Calgary

Calgary, Alberta

Canada T2N IN4

C. Yankee

Yankee Engineering

744 Washington Ave.

Westhaven, CT 05616
No. of

Copies

B. T. Zinn

Georgia Institute of Technology

Atlanta, GA 30321

J. Corliss

Battelle Columbus Laboratories

$505 \mathrm{King}$ Ave.

Columbus, $\mathrm{OH} 43201$

J. Keller

Sandia National Laboratories

Livermore, CA 94550

ONSITE

DOE Richland Operations

H. E. Ransom/D. R. Segna

34 Pacific Northwest Laboratory

H. J. Bomelburg (5)

D. L. Brenchley (20)

D. C. Kuick

R. G. Rivera

Publishing Coordination MH (2)

Technical Information (5) 